Electronic Noise and Low Noise Design 


\section{Macmillan New Electronics Series}

Series Editor: Paul A. Lynn

Rodney F. W. Coates, Underwater Acoustic Systems

W. Forsythe and R.M. Goodall, Digital Control

C. G. Guy, Data Communications for Engineers

Paul A. Lynn, Digital Signals, Processors and Noise

Paul A. Lynn, Radar Systems

A. F. Murray and H. M. Reekie, Integrated Circuit Design

F. J. Owens, Signal Processing of Speech

Dennis N. Pim, Television and Teletext

M.J.N. Sibley, Optical Communications

Martin S. Smith, Introduction to Antennas

P.M. Taylor, Robotic Control

G.S. Virk, Digital Computer Control Systems

Allan Waters, Active Filter Design

\section{Series Standing Order}

If you would like to receive future titles in this series as they are published, you can make use of our standing order facility. To place a standing order please contact your bookseller or, in case of difficulty, write to us at the address below with your name and address and the name of the series. Please state with which title you wish to begin your standing order. (If you live outside the UK we may not have the rights for your area, in which case we will forward your order to the publisher concerned.)

Customer Services Department, Macmillan Distribution Ltd, Houndmills, Basingstoke, Hampshire, RG21 2XS, England 


\title{
Electronic Noise and \\ Low Noise Design
}

\author{
Peter J. Fish
}

MSc, FInstP, FIPSM, CEng, CPhys, Sen. Mem. IEEE

Senior Research Fellow, School of Electronic Engineering Science

University of Wales, Bangor

and

Consultant Medical Physicist

Gwynedd and Clwydd Health Authorities 
All rights reserved. No reproduction, copy or transmission of this publication may be made without written permission.

No paragraph of this publication may be reproduced, copied or transmitted save with written permission or in accordance with the provisions of the Copyright, Designs and Patents Act 1988, or under the terms of any licence permitting limited copying issued by the Copyright Licensing Agency, 90 Tottenham Court Road, London WIP 9HE.

Any person who does any unauthorised act in relation to this publication may be liable to criminal prosecution and civil claims for damages.

First published 1993 by

THE MACMILLAN PRESS LTD

Houndmills, Basingstoke, Hampshire RG21 2XS and London

Companies and representatives

throughout the world

ISBN 978-0-333-57310-5

ISBN 978-1-349-23060-0 (eBook)

DOI 10.1007/978-1-349-23060-0

A catalogue record for this book is available from the British Library. 
To Kathryn and Marianne 


\section{Contents}

Series Editor's Foreword xii

Preface xiii

1 Introduction 1

1.1 Definition 1

1.2 Noise categories 1

1.3 Effect of noise $\quad 2$

1.4 Low noise design 4

2 Random Signals 6

2.1 Introduction $\quad 6$

2.2 Elements of probability 6

2.2.1 Probability of events 6

2.2.2 Conditional probability and independence 7

2.2.3 Discrete random variable 8

2.2.4 Continuous random variable 9

$\begin{array}{ll}2.2 .5 \text { Means } & 11\end{array}$

2.2.6 Gaussian probability density function 13

2.2.7 Central limit theorem 13

$\begin{array}{ll}2.2 .8 \text { Correlation } & 13\end{array}$

2.2.9 Measurement errors $\quad 15$

$\begin{array}{ll}2.3 \text { Random processes } & 16\end{array}$

2.3.1 Introduction $\quad 16$

$\begin{array}{ll}\text { 2.3.2 Means } & 17\end{array}$

2.3.3 Autocorrelation and cross-correlation functions $\quad 17$

2.3.4 Stationary processes 18

2.3.5 Ergodic processes $\quad 19$

2.4 The frequency domain $\quad 20$

2.4.1 Introduction $\quad 20$

2.4.2 The Fourier transform 21

2.4.3 Energy and power spectra 23

2.4.4 Linear systems $\quad 26$

2.4.5 Cross-power spectra 28

$\begin{array}{ll}\text { Reference } & 30\end{array}$ 
viii

Contents

3 Noise Connected with Layout or Construction 31

3.1 Introduction 31

3.2 Field-coupled noise $\quad 32$

$\begin{array}{lll}3.2 .1 & \text { Introduction } & 32\end{array}$

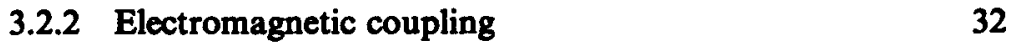

3.2.3 Magnetic (mutual inductance) coupling 35

3.2.4 Electric (capacitative) coupling 43

3.3 Conducted noise $\quad 51$

3.3.1 Introduction 51

3.3.2 Common signal path 51

$\begin{array}{ll}\text { 3.3.3 Power supplies } & 59\end{array}$

3.3.4 Power-line borne noise 61

3.4 Noise of non-electrical origin 61

3.4.1 Introduction 61

3.4.2 Triboelectric noise 63

3.4.3 Conductor movement in magnetic field 65

3.4.4 Piezoelectric effect 65

3.4.5 Space charge effects 66

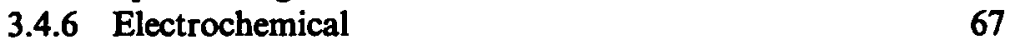

$\begin{array}{lll}3.4 .7 & \text { Thermal } & 68\end{array}$

$\begin{array}{lll}3.4 .8 \text { Contact noise } & 70\end{array}$

$\begin{array}{ll}\text { References } & \mathbf{7 0}\end{array}$

4 Intrinsic Noise $\quad 72$

$\begin{array}{ll}4.1 \text { Introduction } & 72\end{array}$

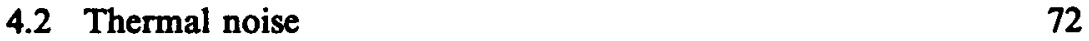

$\begin{array}{lll}\text { 4.2.1 Introduction } & 72\end{array}$

4.2.2 Noise specification and dependence on bandwidth 75

4.2.3 Temperature dependence 75

$\begin{array}{ll}\text { 4.2.4 Available power } & 76\end{array}$

4.2.5 Normalised power spectrum and noise bandwidth 76

4.2.6 Thermal noise from mixed resistive and reactive $\begin{array}{ll}\text { sources } & 81\end{array}$

4.2.7 Non-electrical sources and equivalent circuits 82

$\begin{array}{lll}4.3 & \text { Shot noise } & 82\end{array}$

4.4 Low frequency (excess) noise $\quad 84$

$\begin{array}{lll}\text { 4.4.1 Introduction } & 84\end{array}$

$\begin{array}{ll}\text { 4.4.2 Noise characteristics } & 85\end{array}$

4.4.3 Excess noise in resistors $\quad 88$

4.5 Burst (popcorn) noise 88

$\begin{array}{ll}\text { References } & 90\end{array}$ 
5 Noise Circuit Analysis 91

5.1 Introduction $\quad 91$

5.2 Networks $\quad 92$

$\begin{array}{lll}\text { 5.2.1 Introduction } & 92\end{array}$

5.2.2 Two-terminal or one-port networks 92

$\begin{array}{ll}\text { 5.2.3 Noise temperature } & 95\end{array}$

5.2.4 Spot frequency and broadband measurements 95

$\begin{array}{ll}\text { 5.2.5 Equivalent noise resistance } & 95\end{array}$

$\begin{array}{ll}\text { 5.2.6 Two-port networks } & 96\end{array}$

$\begin{array}{ll}\text { 5.2.7 Equivalent noise resistance } & 101\end{array}$

5.2.8 Amplifier noise temperature 102

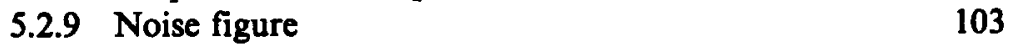

5.2.10 Achieving noise matching 109

$\begin{array}{ll}5.2 .11 \text { Feedback } & 110\end{array}$

5.2.12 Cascaded, matched networks $\quad 113$

5.2.13 Noise figure of matched attenuator $\quad 115$

5.2.14 Two-port network with correlated equivalent noise generators $\quad 116$

$\begin{array}{ll}\text { References } & 120\end{array}$

6 Noise Models 122

6.1 Introduction $\quad 122$

$\begin{array}{ll}6.2 \text { Resistor } & 122\end{array}$

$\begin{array}{ll}6.3 \text { Capacitor } & 123\end{array}$

$\begin{array}{ll}6.4 \text { Inductor } & 124\end{array}$

$\begin{array}{ll}6.5 \text { Transformer } & 124\end{array}$

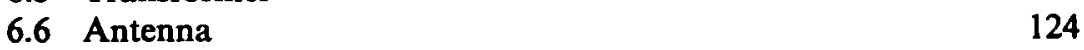

$\begin{array}{ll}\text { 6.7 Semiconductor diode } & 126\end{array}$

$\begin{array}{ll}6.8 \text { Bipolar transistor } & 128\end{array}$

$\begin{array}{ll}6.9 \text { FET } & 140\end{array}$

References $\quad 143$

7 Noise Performance Measurement $\quad 145$

$\begin{array}{lll}7.1 & \text { Introduction } & 145\end{array}$

$\begin{array}{ll}7.2 \text { Noise level measurement } & 145\end{array}$

$\begin{array}{ll}\text { 7.2.1 Accuracy requirement } & 145\end{array}$

$\begin{array}{ll}7.2 .2 \text { Oscilloscope } & 146\end{array}$

$\begin{array}{ll}\text { 7.2.3 Audio analysis } & 148\end{array}$

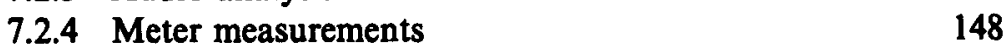

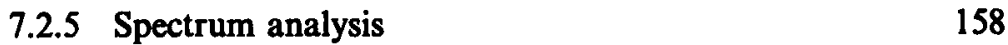


7.3 Noise figure measurement 163

7.3.1 Introduction 163

7.3.2 Sine-wave method 164

7.3.3 Noise generator method 168

$\begin{array}{ll}\text { 7.3.4 Temperature correction } & 172\end{array}$

$\begin{array}{lll}\text { 7.3.5 Mixing down } & 172\end{array}$

7.3.6 Power meter noise correction 174

7.3.7 Comparison of sine-wave and noise generator
methods

7.4 Noise temperature measurement 176

7.5 Noise figure variation with source impedance, and noise parameters $\quad 176$

7.6 Noise generators 178

$\begin{array}{ll}7.7 \text { Active devices } & 180\end{array}$

7.8 Very low frequency noise 184

7.9 Excess noise in resistors 184

$\begin{array}{ll}7.10 \text { Measurement tips } & 189\end{array}$

References $\quad 190$

8 Computer Modelling 192

8.1 Introduction 192

8.2 SPICE 193

8.2.1 Introduction 193

8.2.2 Input file 193

8.2.3 Analyses and output 195

8.2.4 Device models 197

$\begin{array}{ll}\text { 8.2.5 Sub-circuits } & 200\end{array}$

8.2.6 Noise generators 201

8.2.7 Noise analysis example 206

References $\quad 209$

9 Low Noise Design $\quad 210$

9.1 Introduction 210

9.2 Layout/construction (electromagnetic compatibility) 210

$\begin{array}{ll}\text { 9.2.1 Introduction } & 210\end{array}$

9.2.2 Preamplifier 211

9.2.3 Shielding 211

9.2.4 Screened cables 227

9.2.5 Low noise cabling and grounding 234

9.2.6 Breaking the ground loop 238

9.2.7 Grounding 240

$\begin{array}{lll}9.2 .8 & \text { Filtering } 240\end{array}$ 
9.3 Intrinsic noise 243

9.3.1 Introduction $\quad 243$

9.3.2 Noise matching 243

$\begin{array}{ll}\text { 9.3.3 Device selection } & 247\end{array}$

9.3.4 Choice of input stage 247

9.3.5 Feedback 249

$\begin{array}{ll}\text { 9.3.6 Biasing } & 249\end{array}$

References $\quad 252$

Appendix A: Constants $\quad 254$

Appendix B: Noise Model of Linear Two-port Network 255

Appendix C: Noise Descriptors 258

Appendix D: Dipole Fields $\quad 260$

Exercises $\quad 264$

Bibliography and Review Articles 269

Answers to Exercises

$\begin{array}{ll}\text { Index } & 273\end{array}$ 


\section{Series Editor's Foreword}

The rapid development of electronics and its engineering applications ensures that new topics are always competing for a place in university and polytechnic courses. But it is often difficult to find suitable books for recommendation to students, particularly when a topic is covered by a short lecture module, or as an 'option'.

This Series offers introductions to advanced topics. The level is generally that of second and subsequent years of undergraduate courses in electronic and electrical engineering, computer science and physics. Some of the authors will paint with a broad brush; others will concentrate on a narrower topic, and cover it in greater detail. But in all cases the titles in the Series will provide a sound basis for further reading of the specialist literature, and an up-to-date appreciation of practical applications and likely trends.

The level, scope and approach of the Series should also appeal to practising engineers and scientists encountering an area of electronics for the first time, or needing a rapid and authoritative update.

Paul A. Lynn 


\section{Preface}

Noise is a problem in many electronic circuits and systems. Arising from the random movement of electrons in circuit elements (intrinsic noise) or from spuriously coupled signals from other circuits and systems (interference), it corrupts the signal of interest and introduces an uncertainty into the information it contains.

Intrinsic noise and interference are usually treated separately. The latter is normally the subject of books on electromagnetic compatibility (EMC). However the problems caused by both types of noise are similar and there is good reason for treating them together. Indeed it is often important for the design engineer to keep both types of noise in mind even when concentrating on one. For example, there is usually little point in incorporating shielding in a design in order to reduce interference well below the noise level determined by intrinsic noise.

This book covers both types of noise, and, within the category of interference, in addition to noise introduced by electric and magnetic fields, noise arising from the transduction of mechanical and thermal disturbances is described. In all cases the means of reducing noise to acceptable or minimum achievable levels are described.

The book aims to provide an introduction to the problem of noise from the viewpoint of a circuit designer, covering the theory of intrinsic noise, electromagnetic compatibility and the basis of low noise design. It will be of value to final year and postgraduate electronic engineering students taking courses on electronic noise or EMC, to postgraduate research students whose projects include low noise design and to practising engineers whose qualifying courses covered the subject inadequately or who need to refresh or improve their knowledge of this area of electronic engineering.

The author's interest in this subject arises from a 24-year involvement in medical instrumentation, dealing with low level signals in circuits with a wide range of impedance levels and from sub-audio to radio frequencies. The book, it is hoped, reflects this range, and all readers, whether concerned with signals from chemical sensors with time constants measured in seconds or with telemetry signals with bandwidths measured in megahertz, should find something of value.

A major group of noise signals is random in nature and, since these signals are often poorly understood, a chapter on the properties and the 
characterisation of random signals is included - providing theoretical background to the following chapters and to further reading. The various types of interference, both of electrical and non-electrical origin, and which are influenced strongly by the physical design of equipment, are described in chapter 3. Intrinsic noise, determined by circuit design, is covered in chapter 4. The methods of noise circuit analysis and noise models of common circuit elements are described in chapters 5 and 6 respectively. Chapter 7 covers the techniques of noise measurement and chapter 8 the use of industry-standard circuit-simulation software SPICE in intrinsic noise analysis. The lessons of the previous chapters, particularly 3 to 6 , are brought together in chapter 9 which describes the methods of low noise design - covering the basic theory and techniques of electromagnetic compatibility and the methods of minimising intrinsic noise.

SI units are used throughout. In particular it should be noted that distances are in metres unless otherwise stated. The term power-line rather than mains is used and power-line frequencies of 50 and $60 \mathrm{~Hz}$ are used in examples and exercises. Negative exponents rather than '\%' are used in most units. For example, intrinsic noise levels are expressed in $\mathrm{VHz}^{-1 / 2}$ rather than $\mathrm{V} / \sqrt{ } \mathrm{Hz}$.

Some of the exercises at the end of the book are adapted from my final year BEng Electronic Engineering exam questions. The permission of the University of Wales to use these questions is gratefully acknowledged.

My thanks are due also to many friends and colleagues who, often without realising it, imparted their enthusiasm for this Cinderella area of electronic engineering or gave me the opportunity to study it. I am particularly indebted to Dr Keith Battye who introduced me to the problem and challenge of noise in electromyography and who enabled me to study it in other areas of medical instrumentation, and to Professor John O'Reilly and Dr Peter Smith for giving me the opportunity to extend my interest, in teaching and production of this book. I should also like to thank Katie Parry for cheerfully typing much of the manuscript, Tony Griffiths for his artistic expertise and my final year students who, without knowing it, encouraged my production of this book in the hope that it might improve their exam grades! Special thanks are due to my family who tolerated my absence from normal family activities over a considerable period of time. 